\title{
Thermal diffusivity and thermal conductivity of dispersed glass sphere composites over a range of volume fractions
}

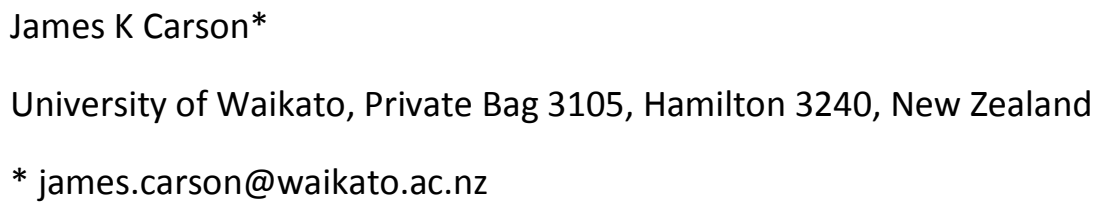

\begin{abstract}
Glass spheres are often used as filler materials for composites. Comparatively few articles in the literature have been devoted to the measurement or modelling of thermal properties of composites containing glass spheres, and there does not appear to be any reported data on the measurement of thermal diffusivities over a range of filler volume fractions. In this study, the thermal diffusivities of guar-gel/glass sphere composites were measured using a transient comparative method. The addition of the glass beads to the gel increased the thermal diffusivity of the composite, more than doubling the thermal diffusivity of the composite relative to the diffusivity of the gel at the maximum glass volume fraction of approximately 0.57 . Thermal conductivities of the composites were derived from the thermal diffusivity measurements, measured densities and estimated specific heat capacities of the composites. Two approaches to modelling the effective thermal diffusivity were considered.
\end{abstract}

Keywords: thermal diffusivity, thermal conductivity, glass spheres, composites

\section{Introduction}

Composite materials offer advantages over single-component, homogeneous materials in that desirable properties of two or more component materials may be combined to produce a material that may be customised for a given application. For example, metal powders may be added to 
polymeric materials to enhance the thermal and mechanical properties of the material, while

\section{Materials and Methods}

\subsection{Materials}


In order to measure thermal diffusivity of glass-sphere dispersions for a range of filler volumes, a

\subsection{Methods}

The thermal diffusivity was measured using a transient comparative method that has been described previously [13]. Briefly, the method involves heating or cooling two samples having the same geometry (spheres in this case), one of which is a control or reference sample having known thermal properties while the other is the test sample of unknown thermal properties. The logarithms of the dimensionless temperature changes ( $\theta)$ defined by Eq. (1) of the samples are plotted against time (Figure 1). 
$\theta=\frac{T(t)-T_{\infty}}{T_{i}-T_{\infty}}$

The linear portion of the temperature histories may be fitted by Eq. (2):

$\ln \theta=F-s t$

where $s$ is the slope and $F$ is the intercept. By comparison with the analytical solution for transient conduction in a sphere for a Fourier number greater than 0.2 (Chapter4, [25]), it can be seen that $s$ is related to the sample's thermal diffusivity according to Eq. (3):

$S=\frac{\lambda^{2} \alpha}{R^{2}}$

where $\alpha$ is thermal diffusivity, $R$ is the radius of the sample and $\lambda$ is the first root of Eq. (4):

$\lambda \cot \lambda+B i-1=0$

where $B i$ is the Biot number:

$B i=\frac{h R}{k}$

where $h$ is the heat transfer coefficient around the sample, and $k$ is the thermal conductivity of the sample. Provided the radii of the test and control samples are the same and Biot numbers of the samples are high enough (e.g. $>100$ ) the ratio of the slopes of the linear portions of the temperature history is directly proportional to the ratios of the thermal diffusivity [13], i.e:

$\frac{\alpha_{e}}{\alpha_{c}}=\frac{s_{e}}{s_{c}}$

where the subscript $e$ refers to the test sample and the subscript $c$ refers to the control or reference sample.

Heat transfer coefficients were estimated using back-calculation from cooling histories of a copper sphere using the lumped heat capacity approximation [25]. 
In this study, a sample of guar gel that did not contain any glass spheres was used as the reference,

while the test samples contained varying quantities of glass spheres dispersed uniformly throughout the sample volume. The samples were initially equilibrated at approximately $20^{\circ} \mathrm{C}$ before being cooled in an ice/water bath. A schematic of the measurement apparatus is shown in Figure 2. All measurements were replicated at least once.

\section{Results and Discussion}

Figure 3 shows a plot of the mean thermal diffusivities of the test samples relative to the thermal diffusivity of the guar gel reference material $\left(1.4 \times 10^{-7} \mathrm{~m}^{2} \mathrm{~s}^{-1}\right)$, i.e. $\alpha_{e} / \alpha_{c}$. There is a clear increase in thermal diffusivity with increasing filler volume, to the extent that the composite with the maximum filler volume has a thermal diffusivity greater than twice that of the control sample. The error bars in Fig. 3 are based on the standard deviation between replicate measurements at each volume fraction (on average $1.5 \%$ of the mean value at each volume fraction).

As mentioned in the Methods section, the validity of Eq. (6) relies on the Biot number being high enough such that the $\lambda$ roots are asymptotic. In order to test this assumption it was necessary to calculate the thermal conductivity of the samples so that the Biot number may be evaluated by Eq. (5). The thermal conductivity was determined from a rearrangement of the definition of thermal diffusivity [25], i.e.:

$k=\alpha \rho c_{p}$

where $\rho$ is the density of the sample and $c_{p}$ is its heat capacity. The density of the glass spheres was measured via Archimedes' principle to be $2520 \mathrm{~kg} \mathrm{~m}^{-3}$, and the density of the guar gel was $1015 \mathrm{~kg}$ $\mathrm{m}^{-3}$. Since the volumes of the spherical sample containers where known, measurement of the test samples' densities were determined simply by weighing. The density of the test samples increased 
linearly with the increase in the volume of glass added to the gel (Figure 4). The measured densities where compared to the densities predicted by the Eq. (8):

$\rho_{e}=v_{\text {gel }} \rho_{g e l}+v_{\text {glass }} \rho_{\text {glass }}$

The difference between measured densities and densities predicted by Eq. (8) was attributed to the presence of air. The average value of the estimated volume fraction of air was 0.03 . This was considered small enough to be negligible.

Direct measurement of the test samples' specific heat capacity was not practical due to the large sizes of the samples. Instead, they were estimated via Eq. (9):

$c_{P, e}=x_{\text {gel }} c_{P, \text { gel }}+x_{\text {glass }} c_{P, \text { glass }}$

The specific heat capacity of the guar gel as measured by differential scanning calorimetry was 4150 $\mathrm{J} \mathrm{kg}^{-1} \mathrm{~K}^{-1}$. The mass fractions $(x)$ of the glass and the gels could be determined from the volume fractions and densities of the samples using Eq. (10):

$x_{\text {glass }}=\frac{\rho_{\text {glass }} v_{\text {glass }}}{\rho_{e}}$

Since the supplier of the glass beads did not provide specific heat capacity data, a mid-range value of $800 \mathrm{~J} \mathrm{~kg}^{-1} \mathrm{~K}^{-1}$ for glass from the literature was used [25-27]. Figure 5 shows the specific heat capacity of the test samples estimated using Eq. (9) based on the estimated specific heat value of $800 \mathrm{~J} \mathrm{~kg}^{-1} \mathrm{~K}^{-}$ ${ }^{1}$, as well dashed lines indicating the $\pm 10 \%$ uncertainty range of the estimates. It is clear that a $10 \%$ uncertainty in the specific heat capacity of the glass contributes less than $10 \%$ uncertainty to $c_{P, e}$.

The thermal conductivities of the test samples were calculated using Eq. (7) from the measured thermal diffusivity data, the measured density data and the specific heat capacities estimated by Eq. (8). The thermal conductivity was then used to calculate the Biot number, which in turn could be used to calculate $\lambda$ using Eq. (4). The heat transfer coefficient measurements ranged between 1200 
and $1500 \mathrm{~W} \mathrm{~m}^{-2} \mathrm{~K}^{-1}$, which produced $\mathrm{Bi}>100$ for all the samples involved, thereby justifying the use of Eq. (6).

Figure 6 shows the thermal conductivity of the test samples as a function of the volume fraction of glass relative to the thermal conductivity of the guar gel $\left(0.57 \mathrm{~W} \mathrm{~m}^{-2} \mathrm{~K}^{-1}\right)$. The error bars in Figure 5 are based on the estimated uncertainty in the thermal conductivity data of $\pm 5 \%$, which is based on combining the error estimates from the thermal diffusivity, specific heat capacity and density measurements. The increase in thermal conductivity with the addition of glass spheres is not as significant as for thermal diffusivity. This is due to the decrease in specific heat capacity with increasing glass volume that offsets both the increase in thermal conductivity with increasing glass volume and the increase in density with increasing glass volume.

Figure 6 also shows predictions of the Series (Eq. 11) and Parallel (Eq. 12) effective thermal conductivity models which form the upper and lower limits to the thermal conductivity of a heterogeneous material [28], based on an estimated thermal conductivity of the glass spheres of 1.1 $\mathrm{W} \mathrm{m} \mathrm{m}^{-2} \mathrm{~K}^{-1}[25-27]$.

$k_{\text {Series }}=\frac{1}{\frac{v_{\text {glass }}}{k_{\text {glass }}}+\frac{v_{\text {gel }}}{k_{\text {gel }}}}$

$k_{\text {Parallel }}=k_{\text {glass }} v_{\text {glass }}+k_{\text {gel }} v_{\text {gel }}$

Two other models are also plotted in Figure 6, the Maxwell-Eucken model with glass as the dispersed phase [28]:

$k_{e}=k_{\text {gel }} \frac{2 k_{\text {gel }}+k_{\text {glass }}-2\left(k_{\text {gel }}-k_{\text {glass }}\right) v_{\text {glass }}}{2 k_{\text {gel }}+k_{\text {glass }}+\left(k_{\text {gel }}-k_{\text {glass }}\right) v_{\text {glass }}}$

and the Lewis-Nielsen model [32-34]:

$k_{e}=k_{\text {gel }} \frac{1+A B v_{\text {glass }}}{1-B \psi v_{\text {glass }}}$

$A=k_{E}-1$ 
$B=\frac{\frac{k_{\text {glass }}}{k_{\text {gel }}}-1}{\frac{k_{\text {glass }}}{k_{\text {gel }}}+A}$

$\psi=1+\left[\frac{1-v_{\max }}{v_{\max }^{2}}\right] v_{\text {glass }}$

where $k_{E}$ is 2.5 for rigid spheres [32,33] and $v_{\max }$ for these experiments (the maximum filler volume fraction was 0.57 . At lower volume fractions of the glass, the thermal conductivity is modelled well by the Series model, while the Maxwell-Eucken and Lewis Nielsen models also lie within the measurement error bars. As the filler volume increases the measured data move away from the Series model and the Maxwell-Eucken model fits the data more closely.

Surprisingly, there do not appear to be many simple effective thermal diffusivity models in the literature where effective thermal diffusivity may be predicted from components' thermal diffusivities and compositions (i.e. thermal diffusivity equivalents of Eqs. 11 and 12). Instead effective thermal diffusivities tend to be modelled based on effective thermal conductivity, effective specific heat capacity and effective density models (e.g. [29,30]), i.e.:

$\alpha_{e}=\frac{k_{e}}{\rho_{e} c_{P, e}}$

However, Eq. (18) only provides approximations of the effective thermal conductivity of composite materials $[35,36]$, and potentially it would be more accurate to model effective diffusivity directly if the model predictions may be compared to directly measured thermal diffusivity data, rather than data derived from thermal conductivity, specific heat capacity and density using Eq. (18). For example, in this study the use of Eq. (18) to model the measured thermal diffusivity data incorporates the uncertainty in the data for thermal conductivity and specific heat capacity of the glass (which were not measured, but taken from the literature), as well as the uncertainty involved in the effective thermal conductivity and specific heat capacity models. Also, the ratio of the thermal conductivity of the glass to the thermal conductivity of the gel is 1.9; whereas the ratio of the thermal diffusivity of the glass to the thermal diffusivity of the gel is 8.9; hence there is inherently 
more uncertainty in predicting the effective thermal diffusivity than the effective thermal conductivity [31].

Using the approach that has been applied to thermal conductivity, a possible effective thermal diffusivity model could be the weighted mean of the components' thermal diffusivities, as has been suggested previously [37]. Since the harmonic mean (i.e. Series model, Eq.11) fitted the thermal conductivity better than the arithmetic mean, a harmonic mean was used to model thermal diffusivity of the composites (Eq. 19):

$\alpha_{e}=\frac{1}{\frac{v_{\text {glass }}}{\alpha_{\text {glass }}}+\frac{v_{\text {gel }}}{\alpha_{\text {gel }}}}$

Equation 19 is plotted in Figure 3, where it can be seen that it fits the measured thermal diffusivity to some extent, particularly for lower volume fractions of glass. However, unlike the case of thermal conductivity where Eqs. (11) and (12) may be derived from analysis of steady-state conduction resistances in series and parallel, Eq. (19) has no theoretical basis, and is merely an average.

Figure 3 also shows the predictions from Eq. (20), which incorporates the Series thermal conductivity model (Eq. 11) into Eq. (18) and $\rho_{e}$ and $c_{P, e}$ were determined from Eqs. (8) and (9) respectively:

$\alpha_{e}=\frac{k_{\text {Series }}}{\rho_{e} c_{P, e}}$

Equation (20) also provides reasonable fits to the measured data; however, it is worth observing from Figure 3 that Eqs. (19) and (20) produce different results because they are not mathematically equivalent. It is clear, then, that effective thermal conductivity models cannot be converted directly to effective thermal diffusivity models simply by substituting $\alpha$ for $k$. The modelling task is complicated by the fact that thermal conductivity is defined from a steady-state heat transfer analysis, while thermal diffusivity is defined from a transient heat transfer analysis. During transient heat transfer the effective thermal conductivity of a heterogeneous or composite material may vary significantly with time as a temperature 'front' progresses between the centre and the surface of an 
object. Therefore, to be more accurate Eq. (18), should incorporate a time-averaged value for $k_{e}$, rather than a steady-state value. It appears there is scope more work to be done in this area.

\section{Conclusion}

The effective thermal diffusivities of dispersions of glass spheres within a guar gel matrix were measured over a range of volume fractions. The addition of the glass beads to the gel increased the thermal diffusivity of the composite, more than doubling the thermal diffusivity of the composite relative to the diffusivity of the gel at the maximum glass volume fraction of approximately 0.57 . The thermal conductivity of the composite was derived from the thermal diffusivity measurements, measured densities and estimated specific heat capacities of the composites. Of the two approaches that were considered for modelling the effective thermal diffusivity, neither is entirely satisfactory and there is scope for more work on this problem.

\section{References}

1. D. M. Bigg, Polym. Composites, 7(3), 125 (1986)

2. Y. Agari, T. Uno., J. Appl. Polym. Sci., 32, 5705 (1986)

3. I.H. Tavman, J. Appl. Polym. Sci., 62 ,2161 (1996)

4. M. Rusu, N.M. Sofian, C. Ibanescu, D. Rusu, Polym. \& Polym. Composites, 8(6), 427 (2000)

5. N.M. Sofian, M. Rusu, R. Neagu, E. Neagu, J. Thermoplast. Composite Mater., 14, 20 (2001)

6. Ye.P. Mamunya, V.V. Davydenko, P. Pissis, E.V. Lebedev, European Polym. J., 38, 1887 (2002)

7. D. Kumlutas, I.H., Tavman, J. Thermoplast. Composite Mater., 19, 441 (2006) 
8. Nurazreena, L.B. Hussain, H. Ismail, D.M. Mariatti, J. Thermoplast. Composite Mater., 19, 413 (2006)

9. A.S. Luyt, J.A. Molefi, H. Krump, Polym. Degrad. Stab., 91, 1629 (2006)

10. H.S. Tekce, D. Kumlutas, I.H. Tavman, J. Reinforced Plastics Composites, 26, 113 (2007)

11. S.R., Annapragada, D., Sun, S.V. Garimella, Computational Mater. Sci., 40, 255 (2007)

12. V. Chifor, R. Orban, Z. Tekiner, Turker, M., Mater. Sci. Forum, 672, 191 (2011)

13. J.K. Carson, M. Noureldin, Int. Communications Heat Mass Transf., 36(5), 458 (2009)

14. J.K. Carson, Int. Communications Heat Mass Transf., 38(8), 1024 (2011)

15. M. Nikzad, S. H. Masood, I. Sbarski, Mater. \& Design, 32(6), 3448 (2011)

16. J.K. Carson, M. Alsowailem, Polym. \& Polym. Composites, 25(6), 447, (2017)

17. D. Senior, Why use high quality glass spheres in plastics resin systems? Technical Report, Potters Industries Pty Ltd

18. J. Z. Liang, F. H. Li, Polym. Test. 25, 527 (2006)

19. J. Z. Liang, F. H. Li, Polym. Test. 26, 419 (2007)

20. D. Mishra, A. Satapathy, A.Patnaik, Advanced Mater. Res., 445, 526 (2012)

21. L. Běhálek, P. Lenfeld, J. Habr, J. Dobránsky, M. Seidl, B. Jiří, , Key Eng. Mater., 669, 3 (2012)

22. A.S. Doumbia, D. Jouannet, T.E.Falher, L. Cauret, Key Eng. Mater., 611-612, 859 (2014)

23. A.S. Doumbia, A. Bourmaud, D. Jouannet, T. Falher, F. Orange, R. Retoux, L. Le Pluart, L. Cauret, , Polym. Degrad. Stab., 114, 146 (2015)

24. Zwart J, Yovanovich, M. M. (1985), Effective thermal diffusivity of simple packed system of spheres, Proceedings of the ASME National Heat transfer Conference, Denver, Co, USA. 
25. Y. A. Cengel, A. J, Ghajar, Heat and Mass Transfer Fundamentals and Applications, $4^{\text {th }}$ edn.

(McGraw-Hill, New York, 2011)

26. F. P. Incropera, D. P. DeWitt, T. L. Bergman, A. S. Lavine, Fundamentals of Heat Transfer, 6th edn. (Wiley, Hoboken NJ, 2006)

27. J. P. Holman, Heat Transfer, $7^{\text {th }}$ edn. (McGraw-Hill, Singapore, 1992)

28. J. K. Carson, S. J. Lovatt, D. J. Tanner, A. C. Cleland, Int. J. Heat Mass Transf., 48, 2150 (2005)

29. D. F. Jaguaribe, D. E. Beasley, Int. J. Heat Mass Transf., 17(3), 399, 1984

30. X. Zhang, H. Gu, M. Fujii, Int. J. Thermophys., 27(2), 569 (2006)

31. J.K. Carson, J.F. Wang, M.F., North, D.J. Cleland, J. Food Eng., 175, 65 (2016)

32. L.E. Nielsen, Ind. Eng. Chem. Fund., 13(1), 17 (1974)

33. L. E. Nielsen, J. App. Polym. Sci., 17 (12), 3819 (1973).

34. C. Vales-Pinzon, A. Vega-Flick, N. W. Pech-May, J. J. Alvarado-Gil, R. A. Medina-Esquivel, M. A. Zambrano- Arjona, J. A. Mendez-Gamboa, J. Appl. Phys., 120, 205109. (2016).

35. W.P. Schimmel, J.V. Beck, A.B. Donaldson, J. Heat Transfer, 99, 466 (1977)

36. I. Ahmadi, Heat Mass Transfer, 53, 277 (2017)

37. Y. Choi, M. R. Okos, Effects of Temperature and Composition on the Thermal Properties of Foods."In Food Engineering and Process Applications 1:93-101. London: Elsevier Applied Science Publishers (1986).

\section{Nomenclature}

$A$

parameter defined by Eq. (14) 
parameter defined by Eq. (15)

$B i$

Biot number defined by Eq. (5)

$C_{P}$

specific heat capacity $\left(\mathrm{J} \mathrm{kg}^{-1} \mathrm{~K}^{-1}\right)$

intercept of linear portion of temperature history

$h$

heat transfer coefficient $\left(\mathrm{W} \mathrm{m}^{-2} \mathrm{~K}^{-1}\right)$

$k$

thermal conductivity $\left(\mathrm{W} \mathrm{m}^{-1} \mathrm{~K}^{-1}\right)$

$R$

radius $(m)$

$s$

slope of linear portion of temperature history $\left(\mathrm{s}^{-1}\right)$

time (s)

$T$

temperature $\left({ }^{\circ} \mathrm{C}\right)$

$v$

$x$

volume fraction

$\alpha$

thermal diffusivity $\left(\mathrm{m}^{2} \mathrm{~s}^{-1}\right)$

$\theta$

dimensionless temperature change

$\lambda$

roots of Eq. (4)

$\psi$

parameter defined by Eq. (14)

Subscripts

$\infty$

bulk condition 
gel

referring to the guar gel

glass

referring to the glass spheres

i

initial value

$\max$

maximum value

\section{Figure Captions}

Figure 1: Temperature histories for cooling spheres

Figure 2: Experimental apparatus

Figure 3: Measured diffusivity ratios with effective diffusivity model predictions

Figure 4: Measured density ratios for varying glass filler fractions

Figure 5: Estimated specific heat capacity of gel/glass composite for varying glass filler fractions.

Figure 6: Thermal conductivity data derived from thermal diffusivity measurements with effective thermal conductivity model predictions. 


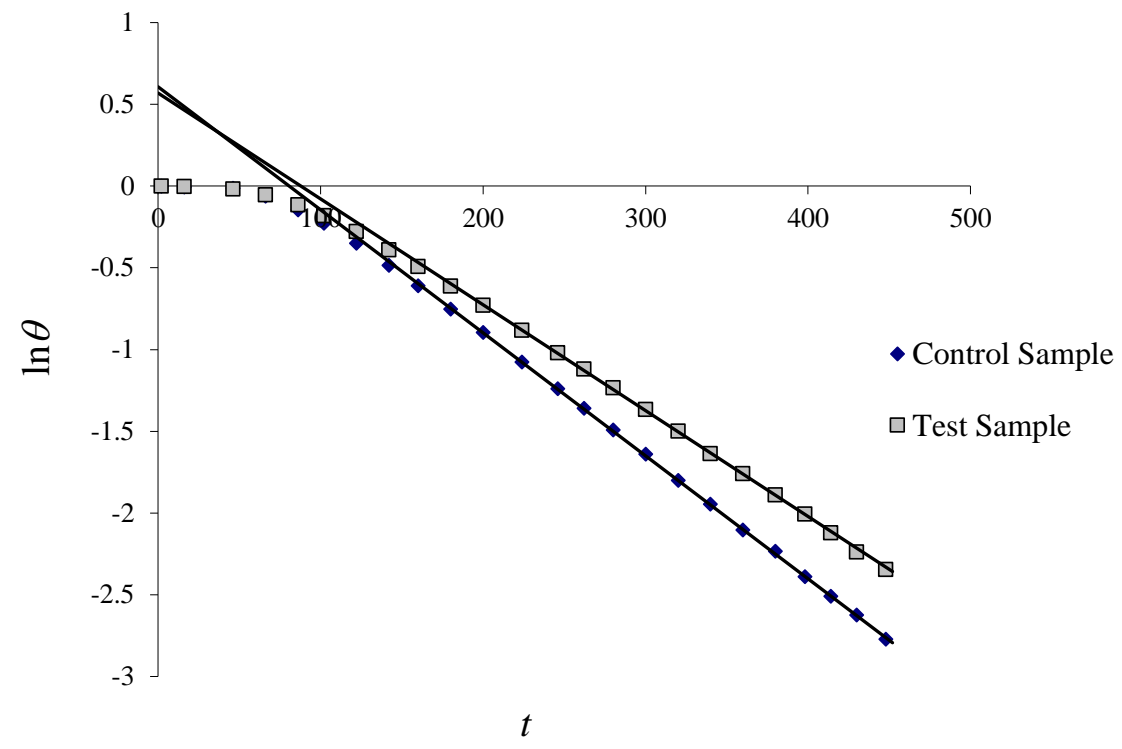

Figure 1 


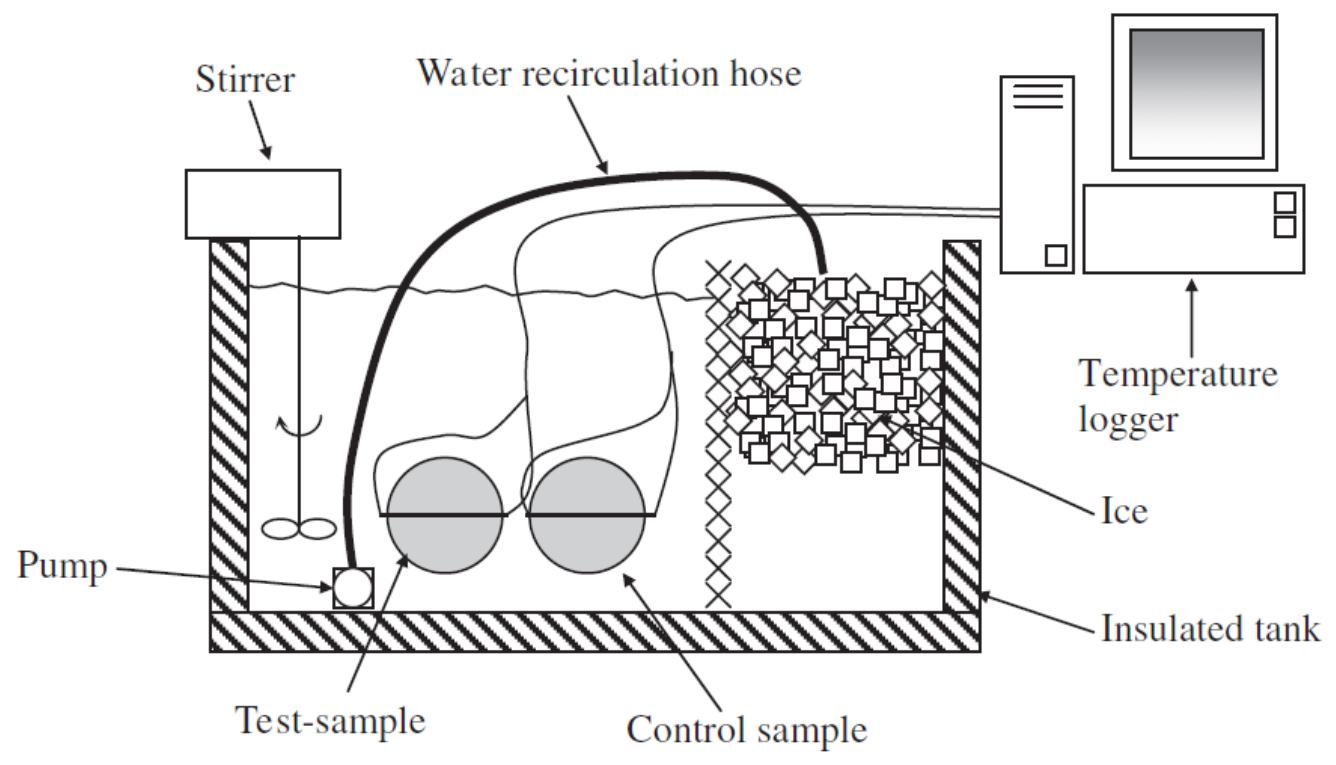

Figure 2 


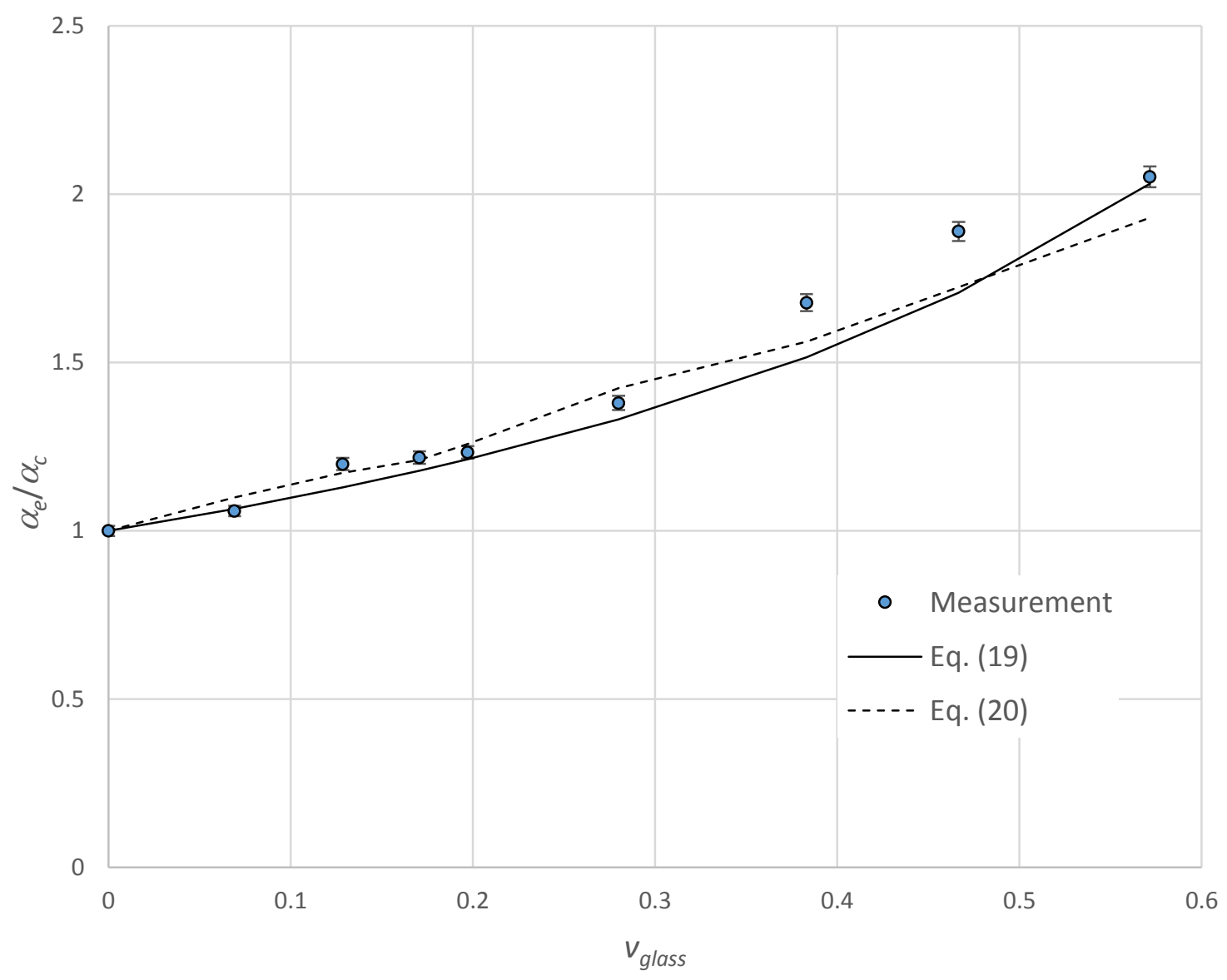

Figure 3 


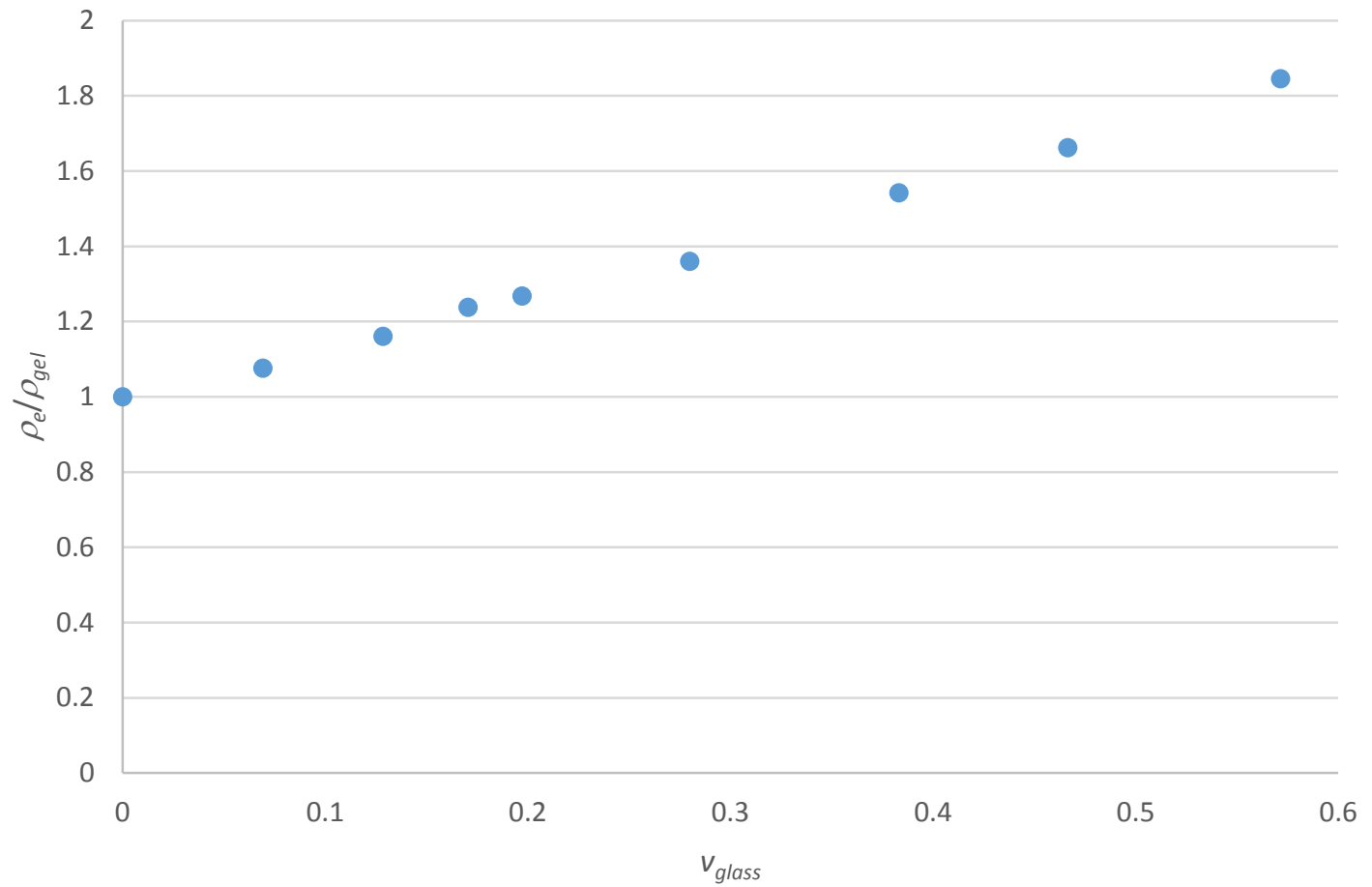

Figure 4 


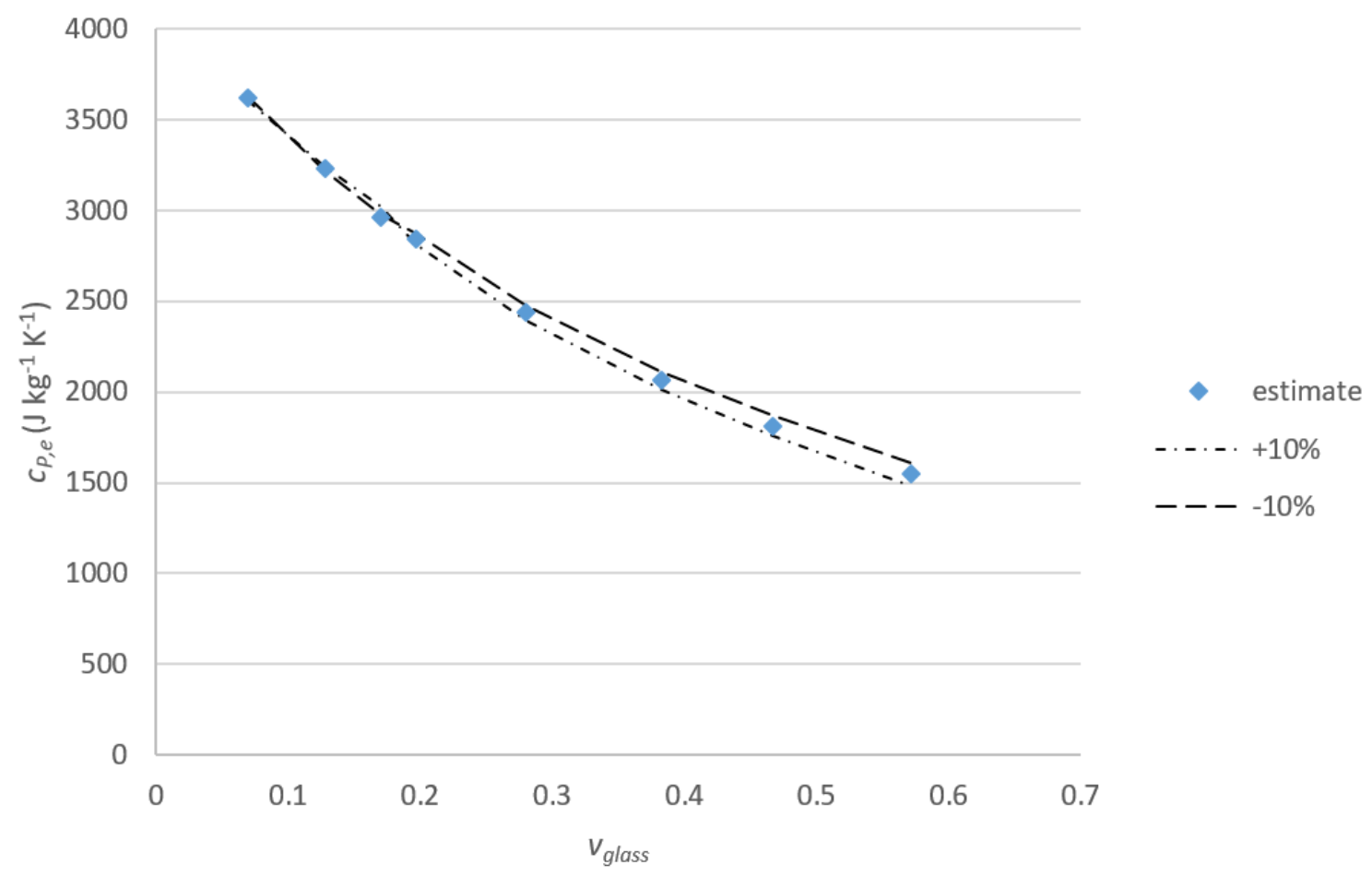

Figure 5 


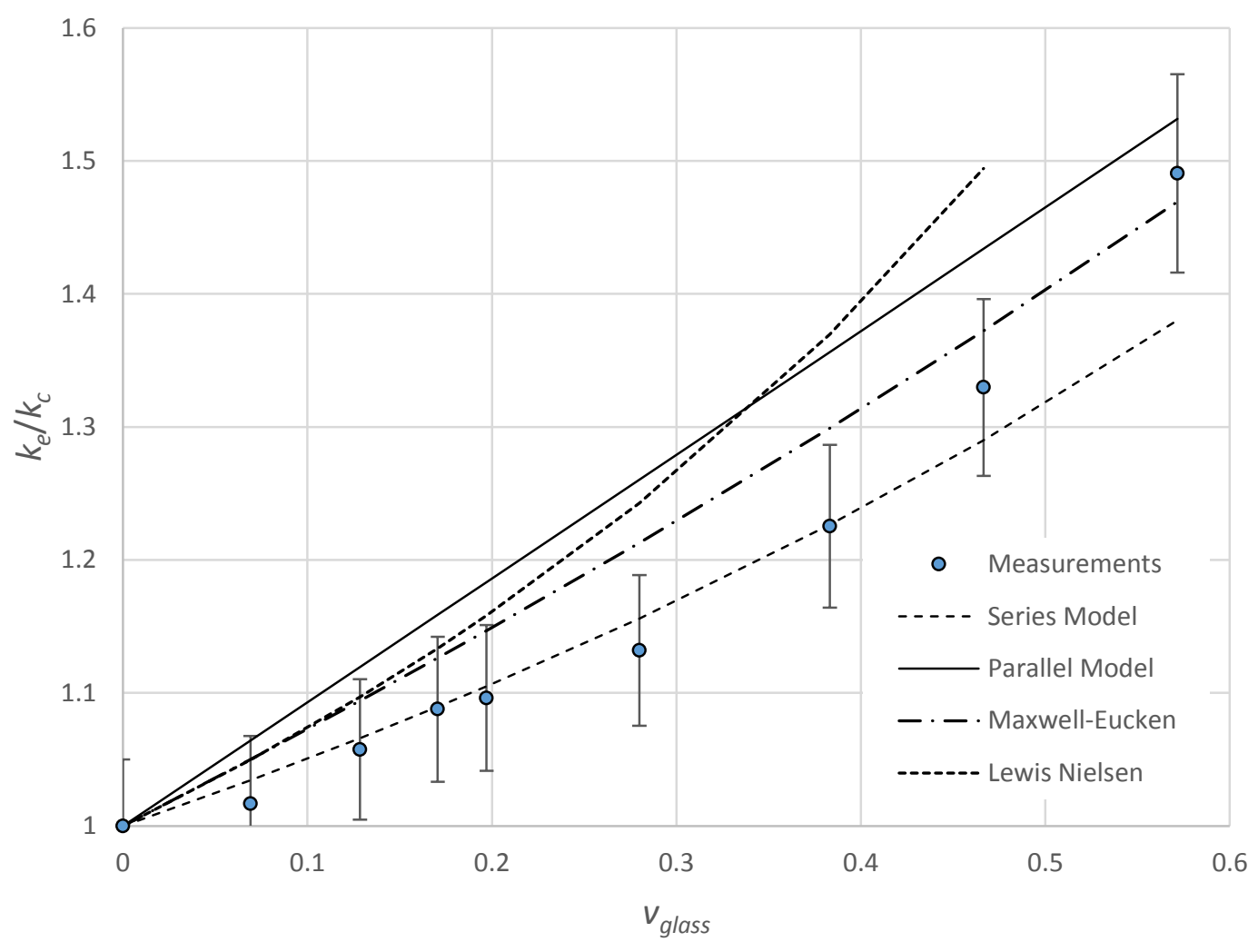

Figure 6 